\title{
Outcome of Uretero Renoscopic Lithotripsy (URSL) with Holmium LASER Vs Pneumatic Lithotripter for Lower Ureteric Stones, Experience from University Hospital of Nepal Joshi HN, Singh AK, Koirala N, Karmacharya RM
}

\author{
Department of Surgery, \\ Dhulikhel Hospital, Kathmandu University Hospital \\ Dhulikhel, Kavre, Nepal.
}

\section{Corresponding Author}

Hem Nath Joshi

Department of Surgery,

Dhulikhel Hospital, Kathmandu University Hospital

Dhulikhel, Kavre, Nepal.

E-mail: hemnjoshi@hotmail.com

\section{Citation}

Joshi HN, Singh AK, Koirala N, Karmacharya RM. Outcome of Uretero Renoscopic Lithotripsy (URSL) with Holmium LASER Vs Pneumatic Lithotripter for Lower Ureteric Stones, Experience from University Hospital of Nepal. Kathmandu Univ Med J. 2020;69(1):49-53.

\begin{abstract}
Background

There are various methods of endoluminal ureteral stone fragmentation. Among various modalities Laser lithotripsy and Pneumatic lithotripsy are commonly used and have shown comparable outcomes.
\end{abstract}

\section{Objective}

To compare the efficacy and outcome of laser and pneumatic lithotripsy in a patient with lower ureteric calculi. The comparison will be done in stone free rate, migration of stone and complication of the procedure.

\section{Method}

This is a prospective comparative study in a cohort of patients at University Hospital with Lower Ureteric stone. Ninety patients were randomized in to two groups (Laser Lithotripsy Vs Pneumatic Lithotripsy) during the study period. The purpose of this study was to measure the immediate stone free rate, intra-operative complications, mean operative time, post-operative complication and if any stone retention after six weeks follow up.

Result

Both the groups were similar in Age and Gender. Immediate stone free rate was slightly higher in Laser lithotripsy group (97.77\%) in comparison to Pneumatic lithotripter group (84.44\%) with $p=0.507$ which is not statistically significant. There was statistical difference in terms of stone migration rate, mean operation time in favor of Laser Lithotripsy group ( $p<0.01$, in both parameters). There were no immediate complications in both the group however there were three cases of short segment ureteric strictures (6.66\%) in case of Pneumatic lithotripsy on six weeks follow up which was managed conservatively.

\section{Conclusion}

Both LASER lithotripter and Pneumatic lithotripter are equally efficacious modality of endoluminal URSL in lower ureteric stone with similar Stone Free Rate. Laser lithotripsy showed lower frequency of stone migration and had shorter procedure time.

\section{KEY WORDS}

Laser lithotripsy, Lower ureteric calculus, Pneumatic lithotripsy 


\section{INTRODUCTION}

Urinary stone disease is one of the most common conditions of the urinary tract, which has plagued humans since the earliest records of civilization. ${ }^{1}$ Incidence of urinary stone disease is varying according to age, gender, occupation and geographic location. Higher prevalence of this disease is found in hot, dry climate or in tropical areas. ${ }^{2}$ In the south East Asia it has been estimated at 5-19.1\%. ${ }^{3}$

The complex cascade events of Physico-chemical process are the root of the pathophysiology of the stone formation in urinary stone disease. Due to presence of stoneinhibiting agents, precipitation of stone forming salts occurs only when super saturation exceeds the solubility by 7 to 11 times. $^{2}$

An optimal outcome of treatment for ureteric stone depends upon number of factors like character, size and location of stone, clinical severity and patient expectations, anatomical conditions, available technical facilities and expertise. Other than conservative management for smaller stones less than $5 \mathrm{~mm}$ size, contemporary treatment options for lower ureteric stones are Extracorporeal Shock Wave Lithotripsy (ESWL), Ureteroscopic Lithotripsy (URSL by using LASER/ Pneumatic/ Ultrasonic), stenting alone, medical expulsive therapy and open ureterolithotomy. ${ }^{4,5}$ Most frequently used contemporary options for intracorporeal endoscopic ureteral stone management are Pneumatic and LASER lithotripters. ${ }^{6-8}$

In Dhulikhel Hospital, Kathmandu University Hospital, we are having pneumatic lithotripter since 2010 and Holmium LASER we have introduced in 2014. Patients are being provided service for ureteral stone management with both modalities. This study was carried out to compare outcome in terms of stone clearance, complication and safety.

\section{METHODS}

This is a prospective, comparative study in the patients presenting to Dhulikhel Hospital Kathmandu University Hospital with Lower Ureteric stone. The study was conducted during March 2017 to June 2018. After receiving ethical clearance from institutional Review committee, the informed consent was taken from all patient involved in the study. Each patient underwent alternative pneumatic lithotripsy or laser lithotripsy.

Sample size was calculated by using proportion formula $n=z^{2} p(1-p) / d^{2}$ where $n=$ required sample size, $z=1.96$ at $95 \%$ confidence interval, $p=$ prevalence of urolithiasis (5\%) and $\mathrm{d}=5 \%$ maximum tolerable error. With This formula; $n=73$. However, for the better yield 90 cases were taken for the study.

Only patients with lower urinary tract stones that is mid ureteric calculi and lower ureteric calculi were taken in to the study. Patients with active Urinary Tract Infection (UTI), coagulopathy, not fit for Spinal Anesthesia, and pregnancy were excluded from the study. All the patients in the study group underwent preoperative Ultrasonography to localize the stone, confirmed with Intravenous Urography and also preoperative Urine culture.

All these patients were performed lithotripsy by two modalities: Pneumatic Lithotripsy (PL) (Group I) and Laser Lithotripsy (LL) (Group II). All patients underwent the procedure under spinal anesthesia. Both groups received a single dose of Pre procedure antibiotics (Injection Ciprofloxacin) 30 minutes before procedure.

In both the group; Uretero-Renoscopy (URS) was done with 9.5 and 7.5 Fr scope (Karl Storz, Germany) semi-rigid scope. Each patient underwent alternative PL or LL. In PL group the pressure was set at $2.5 \mathrm{~kg} / \mathrm{cm}^{2}$, Frequency at 6-8 pulse/sec for all the patients. Similarly, LL group had a power setting of 12 watt with frequency of 8-10 Hz. Laser Machine that we used was 20-Watt Lumenis Holmium Laser, (Lumenis, Israel).

During the procedure stone was fragmented in to pieces. Largest size left after breakdown was less than or equal to $3 \mathrm{~mm}$. Post procedure $6 \mathrm{Fr}$ Double J stent was placed. Any mucosal injury, impacted stones, pus draining from collecting system, perforation, bleeding, and migration of stone or failure of the procedure was noted. If under fluoroscopy, there was absence of any feeling defect in the urinary tract; we labeled it as immediate stone free status. Post-operative fever was documented if present within 48 hours. Placed DJ stent was removed after 6 weeks. On 6 weeks follow up, X-ray KUB was done; it was labeled stone free if no stones more than $3 \mathrm{~mm}$ was noted in the X-ray KUB $100 \%$ magnification. Patient with impacted stones, failed procedure or migrated stone were re-evaluated after 6 weeks during DJ stent removal. Repeat Procedure was performed in cases with failure for stone clearance.

Collected Data were analyzed using SPSS 25.0 Version. Qualitative and quantitative analysis were done using various statistical tools like chi-square test to compare any differences between the groups and independent T-test for the outcome of two treatment groups. $P$ value less than 0.05 was considered statistically significant.

\section{RESULTS}

Out of total 90 patients enrolled in the study; ( $\mathrm{PL}=45$ and $L L=45)$; The age of the patients ranged from 17 to 62 years. The mean of age was $35.4 \pm 11$.0. Demographic and Clinical characteristics of both the group are shown in Table 1. There is no statistically significance in age, sex, laterality of the stone or the location of the stone in both the group. However, the mean stone size in PL group (Group I) was $10.11 \pm 2.03 \mathrm{~mm}$ and mean stone size in LL group (Group II) was $11.51 \pm 3.69 \mathrm{~mm}$ which is statistically significant. The LL group seems to have larger stones. However, both the 
Table 1. Demographic and Clinical Characteristics of two groups

\begin{tabular}{|c|c|c|c|c|}
\hline \multicolumn{2}{|l|}{ Variables } & $\begin{array}{l}\text { Pneumatic } \\
\text { Lithotripsy }\end{array}$ & $\begin{array}{l}\text { Laser } \\
\text { Lithotripsy }\end{array}$ & $\begin{array}{l}\text { Statistics } \\
\text { P value }\end{array}$ \\
\hline \multicolumn{2}{|c|}{ Mean Age $\pm S D$, in Years } & $37.02 \pm 11.80$ & $33.77 \pm 10.14$ & $\begin{array}{l}p \text { value = } \\
0.165\end{array}$ \\
\hline \multirow[t]{2}{*}{ Gender } & Male & 23 & 31 & \multirow{2}{*}{$\begin{array}{l}\text { Chi } \\
\text { square } \\
=2.963 ; \\
\text { p value } \\
=0.851\end{array}$} \\
\hline & Female & 22 & 14 & \\
\hline \multirow{2}{*}{$\begin{array}{l}\text { Stone } \\
\text { Locations }\end{array}$} & Mid Ureter & 21 & 21 & \\
\hline & Distal Ureter & 24 & 24 & \\
\hline \multirow[t]{2}{*}{ Laterality } & Left & 18 & 20 & \\
\hline & Right & 27 & 25 & \\
\hline \multicolumn{2}{|c|}{$\begin{array}{l}\text { Mean Stone Size } \pm \text { SD, } \\
\text { in } \mathrm{mm} \text {. }\end{array}$} & $10.11 \pm 2.03$ & $11.51 \pm 3.69$ & $\begin{array}{l}p \text { value }= \\
0.029\end{array}$ \\
\hline \multirow[b]{2}{*}{$\begin{array}{l}\text { Stone Size } \\
\text { Group }\end{array}$} & $\leq 10 \mathrm{~mm}$ & 27 & 20 & \multirow{2}{*}{$\begin{array}{l}\text { Chi } \\
\text { square } \\
\text { is } 2.182 ; \\
p \text { value } \\
=0.139\end{array}$} \\
\hline & $>10 \mathrm{~mm}$ & 18 & 25 & \\
\hline
\end{tabular}

Table 2. Intra-operative and Post-operative Comparison of two group.

\begin{tabular}{|llll|}
\hline Variables & $\begin{array}{l}\text { Pneumatic } \\
\text { Lithotripsy }\end{array}$ & Laser Lithotripsy & $\begin{array}{l}\text { Statistics } \\
\text { p value }\end{array}$ \\
\hline $\begin{array}{l}\text { Mean Operation Time } \\
\pm \text { SD, in Minute. }\end{array}$ & $33.09 \pm 9.01$ & $23.33 \pm 7.47$ & $<0.01$ \\
\hline $\begin{array}{l}\text { Immediate Stone Free } \\
\text { Rate (SFR) }\end{array}$ & $38(84.44 \%)$ & $44(97.77 \%)$ & 0.507 \\
\hline Migration of Stone & $5(11.11 \%)$ & 0 & $<0.01$ \\
\hline Stone Retained & $2(4.44 \%)$ & $1(2.22 \%)$ & 0.563 \\
\hline Repeat URS & $7(15.55 \%)$ & $1(2.22 \%)$ & $<0.01$ \\
\hline
\end{tabular}

group had no statistically difference in the distribution of stones of size less than $10 \mathrm{~mm}$ and more than $10 \mathrm{~mm}$.

In Table 2. We have documented the operative parameters in both the group. The mean operative duration in LL $(23.33 \pm 7.47$ minutes) group was significantly less than the mean operative time of PL group (33.09 \pm 9.01 minutes). Immediate Stone Free Rate (ISFR) was similar in both the groups. However, stone migration was present only in the $\mathrm{PL}$ group. There were no cases that had stone migration in LL group. There were two cases where stone were not completely fragmented in PL group and one case in LL group.

On the immediate peri-operative period no patient in any group had ureteric perforation, major bleeding or fever. On 6 weeks follow up; there were seven cases in PL group that had residual stone of more than $3 \mathrm{~mm}$ size in the ureter on X-ray KUB (100\% magnification) and one case of residual stone in the LL group. These eight cases all underwent repeat treatment for which we used the URS with LL. During repeat URS 3 cases had a short segment ureteric stricture among PL group; which was managed by stone removal and Double J stent for next 6 wks. These three cases had no residual stricture on further 6 weeks follow up.

\section{DISCUSSION}

Ureteric calculi are one of the major urosurgical problems of a patient who visits to the outpatient department of Urology in DHOS. There are various modalities of treatment and the choice for these modalities depends on the location of stone, size of stone, status of kidney function. In more than $90 \%$ case, ureteric stones smaller than $5 \mathrm{~mm}$ tend to pass spontaneously. ${ }^{4}$ For stones larger than $6 \mathrm{~mm}$ size there is lower rate of spontaneous passage, in such case patients should be counselled about the different treatment options. ${ }^{4,9}$ Similarly stones with less density are possible candidate to undergo Extracorporeal shock wave lithotripsy (ESWL). ${ }^{10}$ In the current era, Endoluminal modalities are first choice of surgery for management of ureteral calculi. The common minimal invasive modalities that are practiced the most for lower ureteric calculi are Pneumatic or laser lithotripsy. Despite both being used globally still there exists a debate between use of these options.

European Association of Urology (EAU) recommends Holmium YAG laser as gold standard procedure for intracorporeal lithotripsy. ${ }^{11}$ The advantage of laser lithotripter is that it can break all type of stone irrespective of its composition and has a low risk of stone migration. ${ }^{12}$

Pneumatic lithotripsy was first practiced in 1992 in Switzerland. ${ }^{13}$ Lower risk of ureteric perforation and no thermal damage is an advantage of pneumatic lithotripter when compared to other lithotripters. ${ }^{14}$ The concern with pneumatic lithotripter is stone migration, that ranges between $1.6 \%$ to $17.3 \% .{ }^{15}$ In our study we found that proximal stone migration was significant in case of PL group ( $11.11 \%$ Vs 0\%). Razzaghi et al. in 2013, reported higher incidence of stone migration with pneumatic lithotripter (17.9\%) and no migration at all in LL group; this is similar to our study. ${ }^{6}$ Similar comparative study was done by Salvado et al. where the author has reported no difference in the stone migration among two groups. ${ }^{16}$ Similarly, Manohar et al. also did not observe any statistically significant difference of stone migration rates among $\mathrm{PL}$ and $\mathrm{LL}$ groups. ${ }^{17}$ In this study the author states that the surgical skills and technological advancement resulted in minimal stone migration even in use of a pneumatic lithotripter.

In the present study, immediate Stone Free Rate (SFR) for lower ureteric calculus with Pneumatic lithotripter was $84.44 \%$ and $97.77 \%$ with Laser $(p=0.507)$ thus similar in both the group with no statistical significance. A study done by Jhanwar et al. in 2016 the authors also reported that the stone free rate for lower ureteric calculi was similar with Pneumatic Vs Laser lithotripter (100\% Vs $94.73 \%) .{ }^{18}$ Similar efficacy has been advocated in many literatures for Laser lithotripter. ${ }^{19}$ Another study reported $100 \%$ immediate SFR in LL group ( $N=12)$ and $42.9 \%$ in $\mathrm{PL}$ group $(\mathrm{N}=14) \mathrm{p}=0.001 .{ }^{20}$ Bapat et al. $97.01 \% \mathrm{SFR}$ in LL group 
Vs $86.01 \%$ SFR in PL group. ${ }^{21}$ Study done by Bapat et al. is contrary to ours as it states Laser lithotripter being superior to pneumatic lithotripter in management of lower ureteric calculi. ${ }^{21}$ Similarly, Salvado et al. reports $96 \%$ SFR with laser lithotripter and Manohar et al. reports $84 \%$ success rate with Laser lithotripter. ${ }^{16,17}$ The SFR with both the modalities seem to be similar in our study too.

Mean operating time in LL group was $23.33 \pm 7.47$ and $33.09 \pm 9.01$ minutes respectively $(p=<0.01)$. We observed that although the mean stone size in LL group was larger than that of PL group $(11.51 \pm 3.69$ Vs $10.11 \pm 2.03)$, the mean operation time seems to be significantly less in LL group. This was similar to other studies done by Jhanwar et al. ${ }^{18}$ where they documented shorter and significantly quicker operation time in LL group.

In this study we retrogradely placed a double J (DJ) stent in all the cases. There are many comparative studies done in past where lithotripsy with or without DJ stent which showed similar outcomes. ${ }^{22}$ In our institution we believe placement of DJ stent prevent urosepsis, urethral stricture and helps in clearance of fragmented stones. In our study none patient suffered from any complication related to URS in both the groups. Some studies have mentioned the complication related to URS to range from 9-25\%, with

\section{REFERENCES}

1. Marshall L. Stoller. Urinary Stone Disease. In: Tanagho E A, McAninch JW, editors. Smith's General Urology. $17^{\text {th }}$ ed. Mc Graw Hill LANGE, 2008: pp. 246-77.

2. Sorokin I, Mamoulakis C, Miyazawa K, Rodgers A, Talati J, Lotan Y. Epidemiology of stone disease across the world. World J Urol. 2017;35(9):1301-20.

3. Liu $\mathrm{Y}$, Chen $\mathrm{Y}$, Liao B, Luo D, Wang $\mathrm{K}$, Li H, et al. Epidemiology of urolithiasis in Asia. 2018 [cited 2020 Apr 21]; Available from: https:// doi.org/10.1016/j.ajur.2018.08.007

4. Ordon M, Andonian S, Blew B, Schuler T, Chew B, Pace KT. CUA guideline: Management of ureteral calculi. J Can Urol Assoc [Internet]. 2015 Dec 1 [cited 2020 Jul 9];9(11-12December):E837-51. Available from: https://www.ncbi.nlm.nih.gov/pmc/articles/PMC4707902/

5. Singal RK, Denstedt JD. Contemporary management of ureteral stones. Urol Clin North Am [Internet]. 1997 [cited 2020 Jul 7];24(1):59-70. Available from: https://pubmed.ncbi.nlm.nih.gov/9048852/

6. Razzaghi MR, Razi A, Mazloomfard MM, Taklimi AG, Valipour R, Razzaghi Z. Safety and efficacy of pneumatic lithotripters versus holmium laser in management of ureteral calculi: A randomized clinical trial. Urol J. 2013;10(1):762-6.

7. Jeon SS, Hyun J-H, Lee K-S. A comparison of holmium:YAG laser with Lithoclast lithotripsy in ureteral calculi fragmentation. Int J Urol [Internet]. 2005 Jun [cited 2020 Jul 9];12(6):544-7. Available from: http://www.ncbi.nlm.nih.gov/pubmed/15985075

8. Garg S, Mandal AK, Singh SK, Naveen A, Ravimohan M, Aggarwal M, et al. Ureteroscopic laser lithotripsy versus ballistic lithotripsy for treatment of ureteric stones: a prospective comparative study. Urol Int [Internet]. 2009 May [cited 2020 Jul 9];82(3):341-5. Available from: http://www.ncbi.nlm.nih.gov/pubmed/19440025

9. Hubner WA, Irby P, Stoller ML. Natural history and current concepts for the treatment of small ureteral calculi. Eur Urol [Internet]. 1993 [cited $2020 \mathrm{Jul}$ 7];24(2):172-6. Available from: https://pubmed.ncbi. nlm.nih.gov/8375436/ major complication to be less than $0.1 \%{ }^{11}$ Mean hospital stay was similar in both the group, the anesthesia was also the same for both group and none of the cases had any complications.

This study was conducted on a limited number of patients and should be considered a pilot study. A future study in a lager population can yield more robust results and have stronger implications for choices between the two lithotripsy techniques in ureteric stone management.

\section{CONCLUSION}

Laser lithotripter and pneumatic lithotripter are equally effictive lithotripsy modalities in lower ureteric calculi using URS with high immediate stone fee rates. However, stone migration and need of repeat procedures are more frequent in case of pneumatic lithotripter giving the advantage to the laser lithotripter.

\section{ACKNOWLEDGEMENT}

Authors would like to thank department of surgery, operation theatre nurses, medical officers and residents who made this study possible.

10. Pereira-Arias JG, Gamarra-Quintanilla M, Urdaneta-Salegui LF, MoraChristian JA, Sánchez-Vazquez A, Astobieta-Odriozola A, et al. [Current status of extracorporeal shock wave lithotripsy in urinary lithiasis.] Arch Esp Urol [Internet]. 2017 Mar [cited 2020 Jul 9];70(2):263-87. Available from: http://www.ncbi.nlm.nih.gov/pubmed/28300033

11. Türk C, Knoll T, Petrik a, Sarica K, Skolarikos a, Straub M, et al. Pocket Guidelines on urolithiasis. Eur Urol [Internet]. 2014;40(4):362-71. Available from: http://www.ncbi.nlm.nih.gov/pubmed/23328170

12. Gerber GS, Brendler CB. Evaluation of the Urologic Patient: History, Physical Examination, and Urinalysis. In: Wein AJ, Kavoussi LR, Novic AC, Partin AW, Peters CA, editors. Campbell-Walsh Urology. $9^{\text {th }}$ ed. Vol 1, Saunders Elsevier 2007: pp 81-110.

13. Denstedt JD, Eberwein PM, Singh RR. The Swiss Lithoclast: A new device for intracorporeal lithotripsy. J Urol [Internet]. 1992 [cited 2020 Jul 9];148(3 II):1088-90. Available from: https://pubmed.ncbi. nlm.nih.gov/1507340/

14. Chen S, Zhou L, Wei T, Luo D, Jin T, Li H, et al. Comparison of Holmium: YAG Laser and Pneumatic Lithotripsy in the Treatment of Ureteral Stones: An Update Meta-Analysis. Urologia Internationalis. S. Karger AG. 2017; Vol. 98: p. 125-33.

15. Menezes $\mathrm{P}$, Kumar PVS, Timoney AG. A randomized trial comparing lithoclast with an electrokinetic lithotripter in the management of ureteric stones. BJU Int [Internet]. 2000 [cited 2020 Jul 9];85(1):22-5. Available from: https://pubmed.ncbi.nlm.nih.gov/10619939/

16. Salvadó JA, Mandujano R, Saez I, Saavedra A, Dell’Oro A, Dominguez J, et al. Ureteroscopic lithotripsy for distal ureteral calculi: Comparative evaluation of three different lithotriptors. J Endourol. 2012 Apr $1 ; 26(4): 343-6$.

17. Manohar T, Ganpule A, Desai M. Comparative evaluation of Swiss LithoClast $2{ }^{\circledR}$ and Holmium:YAG laser lithotripsy for impacted upper-ureteral stones. J Endourol [Internet]. 2008 Mar 1 [cited 2020 Jul 9];22(3):443-6. Available from: https://pubmed.ncbi.nlm.nih. gov/18355139/ 
18. Jhanwar A, Bansal A, Sankhwar S, Kumar M, Kanodia G, Prakash G. Outcome analysis of holmium laser and pneumatic lithotripsy in the endoscopic management of lower ureteric calculus in pediatric patients: A prospective study. Int Braz J Urol. 2016;42(6):1178-82.

19. Leijte JAP, Oddens JR, Lock TMTW. Holmium laser lithotripsy for ureteral calculi: Predictive factors for complications and success. J Endourol [Internet]. 2008 Feb 1 [cited 2020 Jul 9];22(2):257-60. Available from: https://pubmed.ncbi.nlm.nih.gov/18294030/

20. Nour HH, Kamel Al, Elmansy H, Badawy MH, Shabana W, Abdelwahab $A$, et al. Pneumatic vs laser lithotripsy for mid-ureteric stones: Clinical and cost effectiveness results of a prospective trial in a developing country. Arab J Urol [Internet]. 2020;00(00):1-6. Available from: https://doi.org/10.1080/2090598X.2020.1749800
21. Bapat SS, Pai KV, Purnapatre SS, Yadav PB, Padye AS. Comparison of holmium laser and pneumatic lithotripsy in managing upperureteral stones. J Endourol [Internet]. 2007 Dec 1 [cited 2020 Jul 9];21(12):1425-7. Available from: https://pubmed.ncbi.nlm.nih. gov/18186678/

22. Shao Y, Zhuo J, Sun XW, Wen W, Liu HT, Xia SJ. Nonstented versus routine stented ureteroscopic holmium laser lithotripsy: A prospective randomized trial. Urol Res. 2008 Oct;36(5):259-63. 